\title{
Long-term efficacy of a combination of amlodipine and olmesartan medoxomil \pm hydrochlorothiazide in patients with hypertension stratified by age, race and diabetes status: a substudy of the COACH trial
}

\author{
S Oparil ${ }^{1}$, SG Chrysant ${ }^{2}, \mathrm{M}$ Melino ${ }^{3}$, J Lee ${ }^{3}$, S Karki ${ }^{3}$ and R Heyrman ${ }^{3}$ \\ ${ }^{1}$ Division of Cardiovascular Diseases, University of Alabama at Birmingham School of Medicine, \\ Birmingham, AL, USA; ${ }^{2}$ Department of Cardiology, Oklahoma Cardiovascular and Hypertension Center and \\ the University of Oklahoma College of Medicine, Oklahoma City, OK, USA and ${ }^{3}$ Clinical Development, \\ Daiichi Sankyo Pharma Development, Edison, NJ, USA
}

\begin{abstract}
A prespecified subgroup analysis of a 44-week openlabel extension study is presented. The efficacy and safety of the combination of amlodipine (AML) + olmesartan medoxomil (OM), with and without the addition of hydrochlorothiazide (HCTZ), were investigated in patients aged $\geqslant 65$ and $<65$ years, Blacks and non-Blacks and patients with and without type 2 diabetes. After an 8-week double-blind, placebo-controlled portion of the study, patients initiated therapy on AML $5+$ OM $40 \mathrm{mg}$ per day, were uptitrated stepwise to AML $10+O M 40 \mathrm{mg}$ per day, with the addition of HCTZ $12.5 \mathrm{mg}$, and $25 \mathrm{mg}$ if blood pressure (BP) goal was not achieved $(<140 / 90$ or $<130 / 80 \mathrm{~mm} \mathrm{Hg}$ for patients with
\end{abstract}

diabetes). Endpoints included the change from baseline in mean seated systolic BP, mean seated diastolic BP and achievement of BP goal. BP decreased from baseline for all treatments in each prespecified subgroup. By the end of the study, BP goal was achieved in $61.0 \%$ of patients aged $\geqslant 65$ years, $68.1 \%$ of patients aged $<65$ years, $63.3 \%$ of Blacks, $67.8 \%$ of non-Blacks, $26.9 \%$ of patients with diabetes and $72.9 \%$ of patients without diabetes. The combination of $A M L+O M \pm H C T Z$ was efficacious, safe and well tolerated by these subgroups.

Journal of Human Hypertension (2010) 24, 831-838; doi:10.1038/jhh.2010.16; published online 4 March 2010

Keywords: amlodipine; diabetes mellitus; elderly; olmesartan medoxomil; race

\section{Introduction}

Hypertension accounts for nearly 7.1 million deaths worldwide every year and is one of the major causes of cardiovascular disease. ${ }^{1}$ Mortality from ischemic heart disease and stroke doubles with every $20 \mathrm{~mm} \mathrm{Hg}$ systolic blood pressure (SBP) or $10 \mathrm{~mm} \mathrm{Hg}$ diastolic BP (DBP) increase through the $\mathrm{BP}$ range of $115 / 75$ to $185 / 115 \mathrm{~mm} \mathrm{Hg}{ }^{2}$ For this reason, the Seventh Report of the Joint National Committee on Prevention, Detection, Evaluation and Treatment of High Blood Pressure (JNC 7) recommended that

Correspondence: Dr S Oparil, Vascular Biology and Hypertension Program, Division of Cardiovascular Diseases, University of Alabama at Birmingham, 703 19th Street South, ZRB 1034, Birmingham, AL 35294-0007, USA.

E-mail: soparil@uab.edu

Received 21 September 2009; revised 27 December 2009; accepted 21 January 2010; published online 4 March 2010 antihypertensive therapy be initiated with two antihypertensive drugs in patients with SBP $>20 \mathrm{~mm} \mathrm{Hg}$ or DBP $>10 \mathrm{mmHg}$ above recommended goal levels. ${ }^{3}$ The need to treat BP aggressively with two or more antihypertensive drugs to achieve BP control has been underscored by recent randomized controlled outcome trials of antihypertensive treatment such as Antihypertensive and Lipid-Lowering treatment to prevent Heart Attack Trial (ALLHAT), ${ }^{4}$ Valsartan Antihypertensive Longterm Use Evaluation (VALUE), ${ }^{5}$ Anglo-Scandinavian Cardiac Outcomes Trial (ASCOT), ${ }^{6}$ and Avoiding Cardiovascular events through Combination therapy in Patients Living with Systolic Hypertension (ACCOMPLISH). ${ }^{7}$ In these studies, excellent BP control was achieved with two or more drugs, and only a small minority of patients (none in ACCOM$\mathrm{PLISH}^{7}$ by design) were able to remain on monotherapy throughout the course of the trials. The need 
for multiple drug therapy is particularly relevant for difficult-to-treat patients such as those aged $\geqslant 65$ years, Blacks and patients with diabetes mellitus, or those with multiple risk factors that require a more rigorous treatment goal of $<130 / 80 \mathrm{~mm} \mathrm{Hg}$.

The Combination of Olmesartan Medoxomil and Amlodipine Besylate in Controlling High BP (COACH) study showed that the calcium channel blocker (CCB) and angiotensin receptor blocker (ARB) combination of amlodipine (AML) and olmesartan medoxomil (OM) had significantly greater efficacy in reducing SBP and DBP after 8 weeks of therapy compared with monotherapy with either compound. ${ }^{8}$ In the COACH study, AML + OM (10 +20 or $10+40 \mathrm{mg}$ per day) enabled mean seated SBP (SeSBP) reductions from baseline of over $30 \mathrm{~mm} \mathrm{Hg}$ in patients with Stage 2 hypertension and over $40 \mathrm{~mm} \mathrm{Hg}$ in patients with SeSBP $\geqslant 180 \mathrm{~mm} \mathrm{Hg}$ at baseline. ${ }^{9}$ In the same study, an analysis of patients stratified into prespecified subgroups based on age, race and diabetes status showed that AML + OM $(10+40 \mathrm{mg}$ per day $)$ enabled SeSBP reductions from baseline in the range of 29 to $34 \mathrm{~mm} \mathrm{Hg}{ }^{10}$

An analysis is reported here of the long-term efficacy and safety of the combination of AML + OM with and without hydrochlorothiazide (HCTZ) in a 44-week open-label extension (OLE) of the COACH cohort, in prespecified subgroups including age, race and diabetes status. ${ }^{11}$

\section{Materials and methods}

\section{Study design}

This was a 44-week OLE of an 8-week multicenter, randomized, double-blind, placebo-controlled, factorial design study (Figure 1). The study was conducted in accordance with the institutional review board regulations, the Declaration of Helsinki and good clinical practice guidelines. All patients provided written informed consent at screening.
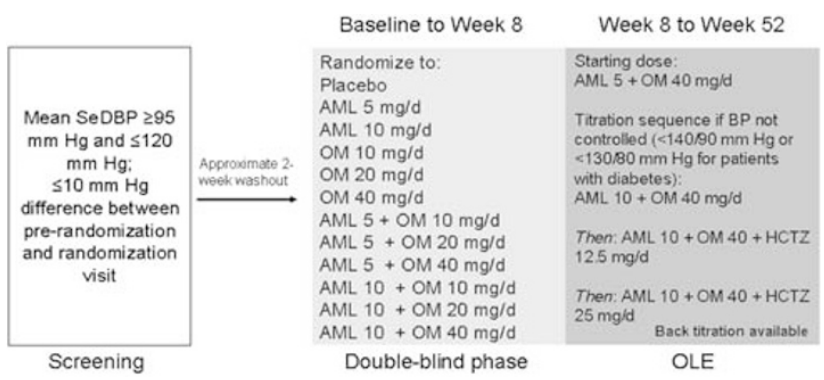

Figure 1 Design of the COACH study. The results of the doubleblind portion have been reported elsewhere. ${ }^{8}$ The open-label portion of the study started all patients $(n=1684)$ on amlodipine (AML) $5 \mathrm{mg}$ + olmesartan medoxomil (OM) $40 \mathrm{mg}$ per day. Patients who did not achieve a minimum blood pressure (BP) goal of $<140 / 90 \mathrm{~mm} \mathrm{Hg}$ (or $<130 / 80 \mathrm{~mm} \mathrm{Hg}$ for patients with diabetes) were titrated to AML $10 \mathrm{mg}+\mathrm{OM} 40 \mathrm{mg}$ per day then hydrochlorothiazide (HCTZ) 12.5 or $25 \mathrm{mg}$ as required to achieve BP goal. OLE, open-label extension; SeDBP, seated diastolic BP.
All medications were provided to patients free of charge. The results of the 8-week double-blind study, including study population, inclusion and exclusion criteria, study design, efficacy variables, safety variables and statistical analyses, have been published elsewhere. ${ }^{8}$ Briefly, for entry into the 8-week double-blind study, patients had a mean SeDBP of 95 to $120 \mathrm{~mm} \mathrm{Hg}$, and a difference of $\leqslant 10 \mathrm{~mm} \mathrm{Hg}$ between the visit before randomization and the randomization visit. This report deals with the portion of the study designed to emulate clinical practice by titrating patients to JNC 7 treatment guideline goals while assessing long-term efficacy and safety.

After completion of the 8-week double-blind portion of the study, ${ }^{8}$ all patients who enrolled into the OLE were switched to the combination of AML $5 \mathrm{mg}+\mathrm{OM} 40 \mathrm{mg}$ per day. Patients whose BP was not adequately controlled (defined as BP $<140 / 90$ or $<130 / 80 \mathrm{~mm} \mathrm{Hg}$ in patients with diabetes) after 2 weeks were titrated to AML $10 \mathrm{mg}+\mathrm{OM} 40 \mathrm{mg}$. Subsequent titrations for inadequate BP control included the addition of HCTZ $12.5 \mathrm{mg}$ and then $25 \mathrm{mg}$ per day. Subjects with adequately controlled BP were maintained at the titrated drug doses. Patients were instructed and reinforced to take their medication at the same time each day, preferably in the morning, though treatment accountability was not assessed at each visit during the OLE of the study. Patients who developed hypotension and/or displayed drug intolerance could be back-titrated at the investigator's discretion.

Standardization across investigator sites was maintained through establishment of a detailed clinical protocol, and procedures at all sites were reinforced by routine protocol monitoring by Medpace Inc. (Cincinnati, OH, USA).

\section{Study population}

Subgroup analyses were prespecified. However, the study was not powered to show statistically significant differences between subgroups. Subgroup analyses were performed for each of the following variables: diabetes status (yes/no), race (Black/ non-Black) and age ( $<65$ and $\geqslant 65$ years).

\section{Efficacy variables}

The efficacy assessments in the OLE included the mean SeSBP and mean seated DBP (SeDBP) by scheduled visit week (Week 8 to Week 52), the effect of dosage titrations or addition of HCTZ on change in SeSBP and SeDBP, and the number and percentage of patients achieving BP treatment goal $(<140 /$ 90 or $<130 / 80 \mathrm{~mm} \mathrm{Hg}$ for patients with diabetes) by scheduled week and treatment regimen and at Week 52/early termination (Week 52/ET).

The Week 52/ET measurement of BP was defined as the value at the end of the study. For patients who terminated before Week 52, the last measurement 
obtained for that patient was carried forward and used in the Week 52/ET summaries. The treatment titration effect was calculated as the BP value at the last visit on the new dosing regimen subtracted from the $\mathrm{BP}$ value at the last visit of the previous dosing regimen.

\section{Safety assessments and evaluation of edema}

Safety was monitored by assessing the incidence of adverse events at each visit. The occurrence and severity of peripheral edema were assessed at all scheduled clinic visits using a unique case report form. When an increase in edema category occurred, investigators were encouraged to report this as an adverse event. If peripheral edema was present, the investigators rated its severity on a case report form using the following 5-point scale: (0) no edema; (1) mild pitting edema/slight indentation; (2) moderate pitting edema/moderate indentation; (3) deep pitting edema/indentation remains and (4) leg remains swollen. If a patient complained of edema, this complaint would be reported as an adverse event, even if the physical assessment did not see a difference from the previous evaluation (reported including the terms edema; edema, peripheral; pitting edema; generalized edema and localized edema).

\section{Results}

\section{Study population}

A total of 1684 patients entered the OLE. The baseline SeBP without any antihypertensive therapy was 163.6/101.5 mm Hg. Mean SeBP was 131.2/81.9 $\mathrm{mmHg}$ in the overall population at Week 52/ET, a decrease of $32.4 \mathrm{~mm} \mathrm{Hg}$ in SeSBP and $19.6 \mathrm{~mm} \mathrm{Hg}$ in SeDBP from baseline. At Week 52/ET, $66.7 \%$ of all patients in the OLE had achieved seated BP (SeBP) goal. ${ }^{11}$ Baseline SeBP characteristics for the total population and selected subgroups (age, race and diabetes status) are summarized in Table 1, based

Table 1 Study cohort mean SeSBP/SeDBP at baseline and Week 52/ET, by subgroup and treatment regimen at Week 52/ET

\begin{tabular}{|c|c|c|c|c|c|}
\hline $\begin{array}{l}\text { Mean } \operatorname{SeBP} \pm \\
\text { s.e.m., } \mathrm{mm} H g\end{array}$ & $\begin{array}{l}\text { AML } 5 \mathrm{mg} / \\
O M 40 \mathrm{mg}\end{array}$ & $\begin{array}{l}A M L 10 \mathrm{mg} / \\
O M 40 \mathrm{mg}\end{array}$ & $\begin{array}{c}\text { AML } 10 \mathrm{mg} / \mathrm{OM} \\
40 \mathrm{mg} / \mathrm{HCTZ} 12.5 \mathrm{mg}\end{array}$ & $\begin{array}{c}\text { AML } 10 \mathrm{mg} / \mathrm{OM} \\
40 \mathrm{mg} / \mathrm{HCTZ} 25 \mathrm{mg}\end{array}$ & $\begin{array}{l}\text { All treatment } \\
\text { regimens }\end{array}$ \\
\hline \multicolumn{6}{|l|}{ Age } \\
\hline \multicolumn{6}{|l|}{$<65$ years } \\
\hline $\mathrm{N}$ & 436 & 306 & 223 & 328 & 1340 \\
\hline Baseline & $155.8 \pm 0.6 / 100.4 \pm 0.2$ & $159.4 \pm 0.7 / 101.4 \pm 0.3$ & $163.1 \pm 0.9 / 102.7 \pm 0.4$ & $169.7 \pm 0.9 / 103.8 \pm 0.3$ & $161.2 \pm 0.4 / 101.9 \pm 0.1$ \\
\hline Week 52/ET & $127.0 \pm 0.6 / 81.5 \pm 0.4$ & $130.3 \pm 0.7 / 82.8 \pm 0.5$ & $129.8 \pm 0.9 / 82.3 \pm 0.6$ & $135.9 \pm 0.8 / 84.4 \pm 0.5$ & $130.3 \pm 0.4 / 82.6 \pm 0.2$ \\
\hline \multicolumn{6}{|l|}{$\geqslant 65$ years } \\
\hline $\mathrm{N}$ & 89 & 72 & 63 & 91 & 331 \\
\hline Baseline & $166.3 \pm 1.7 / 99.9 \pm 0.5$ & $166.4 \pm 1.6 / 99.9 \pm 0.4$ & $173.7 \pm 2.0 / 100.4 \pm 0.4$ & $184.2 \pm 1.6 / 100.9 \pm 0.6$ & $173.1 \pm 0.9 / 100.2 \pm 0.2$ \\
\hline Week 52/ET & $130.6 \pm 1.8 / 78.3 \pm 0.9$ & $133.8 \pm 1.6 / 80.4 \pm 1.0$ & $134.1 \pm 1.9 / 76.5 \pm 1.0$ & $140.2 \pm 1.8 / 79.7 \pm 0.8$ & $134.8 \pm 0.9 / 78.7 \pm 0.5$ \\
\hline \multicolumn{6}{|l|}{ Race } \\
\hline \multicolumn{6}{|l|}{ Black } \\
\hline $\mathrm{N}$ & 84 & 90 & 82 & 147 & 409 \\
\hline Baseline & $156.1 \pm 1.4 / 100.7 \pm 0.6$ & $158.1 \pm 1.3 / 100.9 \pm 0.5$ & $161.1 \pm 1.6 / 102.4 \pm 0.5$ & $172.3 \pm 1.4 / 103.6 \pm 0.5$ & $163.3 \pm 0.8 / 102.2 \pm 0.3$ \\
\hline Week 52/ET & $132.8 \pm 1.7 / 84.0 \pm 1.1$ & $130.6 \pm 1.4 / 83.4 \pm 0.8$ & $129.6 \pm 1.8 / 82.8 \pm 1.0$ & $135.9 \pm 1.4 / 83.7 \pm 0.8$ & $132.6 \pm 0.8 / 83.5 \pm 0.5$ \\
\hline \multicolumn{6}{|l|}{ Non-Black } \\
\hline $\mathrm{N}$ & 441 & 288 & 204 & 272 & 1262 \\
\hline Baseline & $157.9 \pm 0.7 / 100.2 \pm 0.2$ & $161.5 \pm 0.8 / 101.2 \pm 0.3$ & $167.2 \pm 1.0 / 102.1 \pm 0.4$ & $173.2 \pm 1.0 / 102.9 \pm 0.3$ & $163.7 \pm 0.4 / 101.3 \pm 0.1$ \\
\hline Week 52/ET & $126.7 \pm 0.6 / 80.4 \pm 0.4$ & $131.1 \pm 0.7 / 82.0 \pm 0.5$ & $131.2 \pm 0.9 / 80.3 \pm 0.6$ & $137.3 \pm 0.8 / 83.3 \pm 0.5$ & $130.7 \pm 0.4 / 81.3 \pm 0.2$ \\
\hline \multicolumn{6}{|l|}{ Diabetes status } \\
\hline \multicolumn{6}{|l|}{ Yes } \\
\hline $\mathrm{N}$ & 36 & 30 & 44 & 109 & 227 \\
\hline Baseline & $163.6 \pm 3.3 / 99.8 \pm 0.6$ & $159.5 \pm 2.1 / 100.1 \pm 0.7$ & $166.4 \pm 2.2 / 101.2 \pm 0.7$ & $173.3 \pm 1.5 / 101.6 \pm 0.5$ & $168.2 \pm 1.1 / 101.0 \pm 0.3$ \\
\hline Week 52/ET & $130.7 \pm 3.2 / 80.2 \pm 1.5$ & $132.8 \pm 2.8 / 82.2 \pm 1.1$ & $132.1 \pm 2.3 / 79.3 \pm 1.2$ & $136.8 \pm 1.4 / 81.9 \pm 0.7$ & $134.0 \pm 1.1 / 81.0 \pm 0.5$ \\
\hline \multicolumn{6}{|l|}{ No } \\
\hline $\mathrm{N}$ & 489 & 348 & 242 & 310 & 1444 \\
\hline Baseline & $157.2 \pm 0.6 / 100.3 \pm 0.2$ & $160.8 \pm 0.7 / 101.2 \pm 0.2$ & $165.3 \pm 1.0 / 102.4 \pm 0.3$ & $172.7 \pm 1.0 / 103.7 \pm 0.3$ & $162.8 \pm 0.4 / 101.6 \pm 0.1$ \\
\hline Week 52/ET & $127.4 \pm 0.6 / 81.1 \pm 0.4$ & $130.8 \pm 0.7 / 82.4 \pm 0.5$ & $130.5 \pm 0.9 / 81.3 \pm 0.6$ & $136.8 \pm 0.8 / 84.0 \pm 0.5$ & $130.7 \pm 0.4 / 82.0 \pm 0.2$ \\
\hline
\end{tabular}

Abbreviations: AML, amlodipine; ET, early termination; HCTZ, hydrochlorothiazide; OM, olmesartan medoxomil; SeBP, seated BP; SeDBP, seated diastolic BP; SeSBP, seated systolic BP.

Data are expressed as mean \pm standard error of the mean (s.e.m.). Baseline for vital signs was defined as the average of the visit values from the randomization visit (Week 0) and the visit before the randomization visit (Week -1). Only patients with baseline and Week 52/ET blood pressure (BP) measurements are included. Each BP visit value is the mean of three measurements. Age was calculated using the date the patient was randomized.

${ }^{a}$ The no. of treatment regimens may not add to all patients due to some patients receiving non-protocol drug combinations, as noted in the Materials and methods section. 


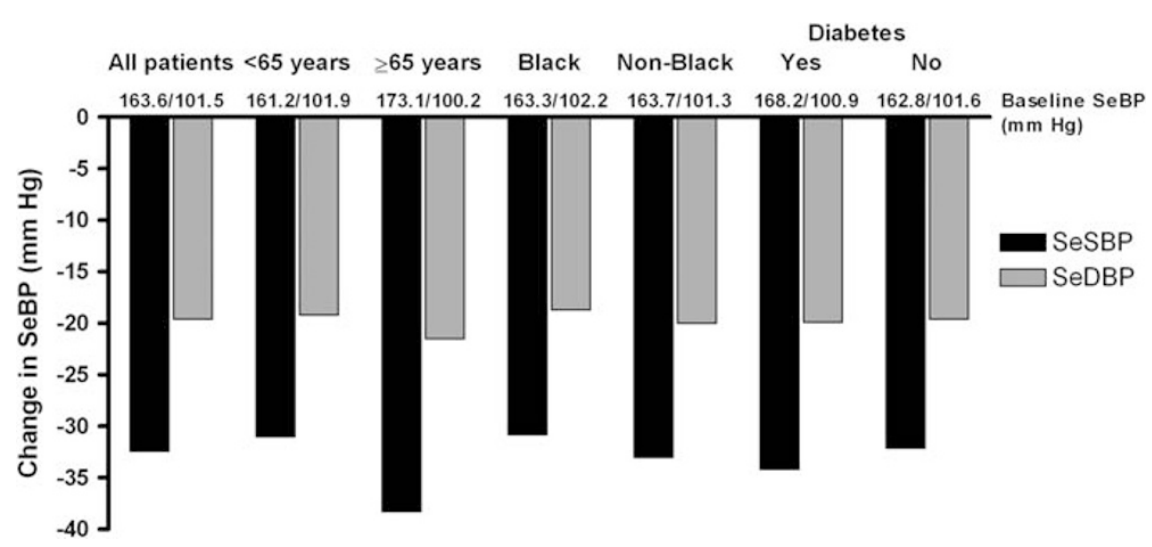

Figure 2 Reductions in seated blood pressure (SeBP) at Week 52/early termination in all patients and by subgroup. SeDBP, seated diastolic BP; SeSBP, seated systolic BP.

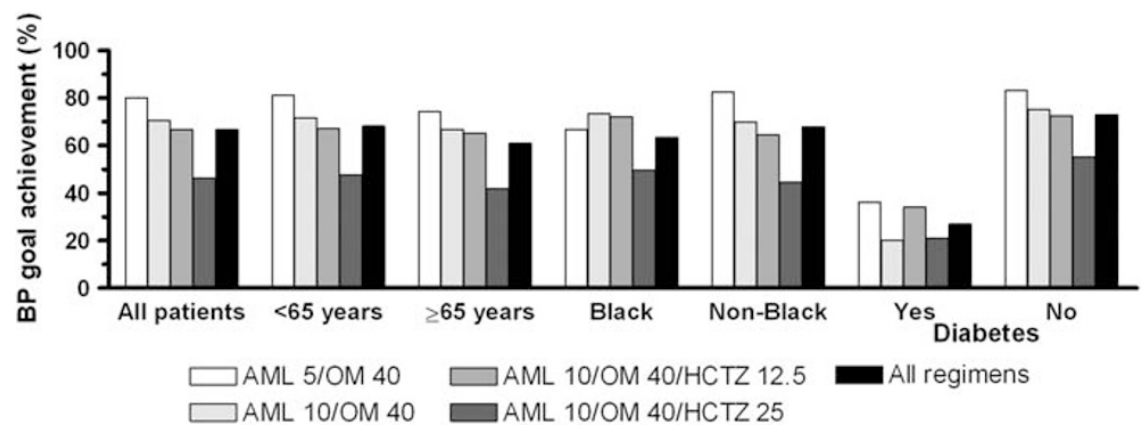

Figure 3 Patients achieving blood pressure (BP) goal at Week 52/early termination, by subgroup and treatment regimen. BP goal was defined as $\mathrm{BP}<140 / 90 \mathrm{~mm} \mathrm{Hg}$ for patients without diabetes and $<130 / 80 \mathrm{~mm} \mathrm{Hg}$ for patients with diabetes. AML, amlodipine; HCTZ, hydrochlorothiazide; OM, olmesartan medoxomil.

upon final treatment regimen at Week 52/ET. The higher SeSBP in older age and diabetes subgroups likely reflects the higher prevalence of elevated SeSBP due to arterial stiffness in these populations. $^{12,13}$ In general, baseline SeSBP was higher in patients subsequently titrated to the more rigorous treatment regimens, including HCTZ. There was little difference in SeDBP at baseline between paired subgroups.

\section{Effect of age}

Mean SeBP decreases for patients aged $<65$ years and $\geqslant 65$ years were $31.0 / 19.2$ and $38.3 / 21.5 \mathrm{~mm} \mathrm{Hg}$, respectively, at Week 52/ET (Figure 2). Baseline SeBP was highest, and SeBP reductions were greater, in patients that were eventually titrated to AML $10 \mathrm{mg}+\mathrm{OM} 40 \mathrm{mg}+$ HCTZ $25 \mathrm{mg}$ per day (Table 1). In general, the addition of HCTZ caused numerically greater SeBP reductions in patients aged $\geqslant 65$ years (Table 1).

In patients aged $<65$ years, $68.1 \% \quad(913 / 1341)$ achieved SeBP goal by Week 52/ET, ranging from 47.6 to $81.2 \%$ across treatment regimens (Figure 3). Among patients aged $\geqslant 65$ years, 61.0\% (202/331) reached their SeBP goal by Week 52/ET, ranging from 41.8 to $74.2 \%$ across treatment regimens (Figure 3). Patients aged $<65$ years had lower baseline SeBP levels and thus were more likely to reach SeBP goals compared with patients aged $\geqslant 65$ years.

The effect of treatment titration was also investigated (Figure 4). Patients aged $\geqslant 65$ years had greater reductions in SeSBP at each titration step, compared with patients aged $<65$ years (Figure 4 ). At each titration step, mean SeSBP decreases were $2.2 \mathrm{~mm} \mathrm{Hg}$ greater for patients aged $\geqslant 65$ than patients aged $<65$ years. Uptitration produced similar mean reductions in SeDBP $(\sim 5.1 \mathrm{~mm} \mathrm{Hg})$ at each dose in patients aged $<65$ years and $\geqslant 65$ years (Figure 4).

\section{Effect of race}

Both the Black and the non-Black subgroups had clinically relevant SeBP decreases from baseline by Week 52/ET (Figure 2). Mean SeBP decreases at Week 52/ET for Black and non-Black patients were $30.8 / 18.7$ and $33.0 / 20.0 \mathrm{~mm} \mathrm{Hg}$, respectively. The baseline SeBP was highest, and the SeSBP reductions were greatest, in patients titrated to AML $10 \mathrm{mg}+$ OM $40 \mathrm{mg}+$ HCTZ $25 \mathrm{mg}$ per day (Table 1). 


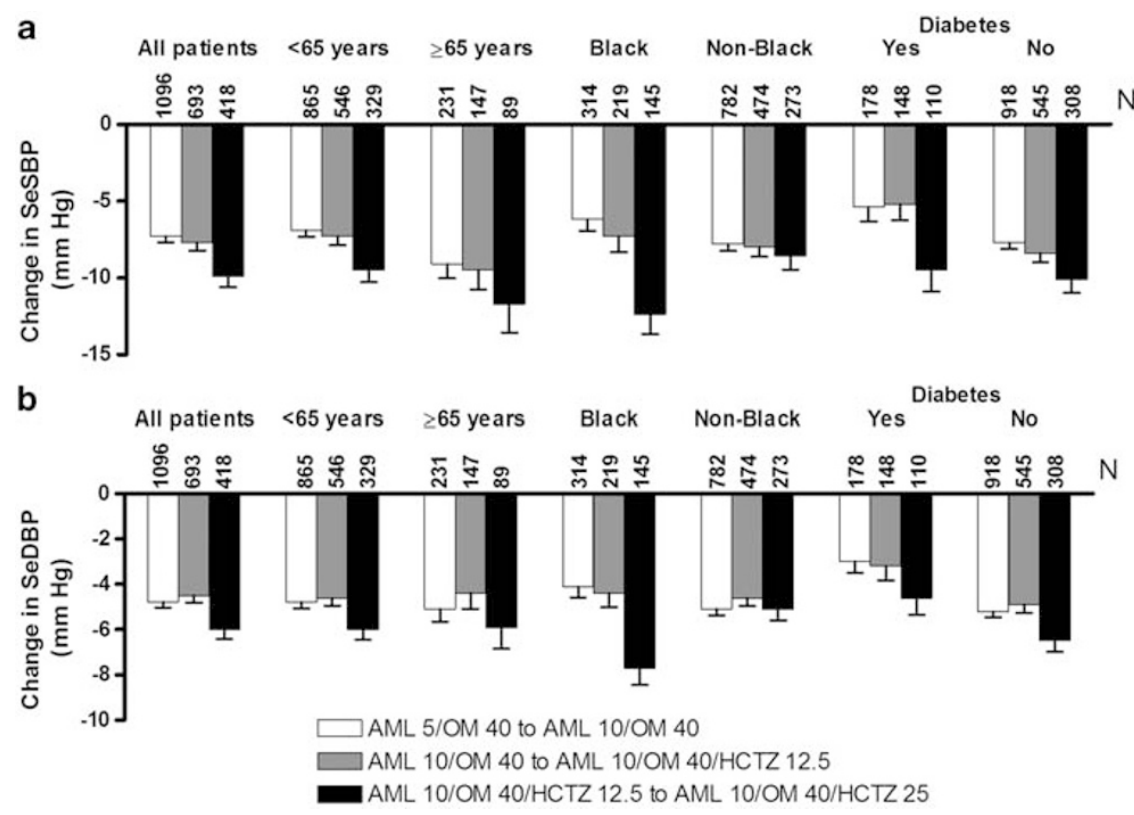

Figure 4 Effect of dosage titration and regimen change on blood pressure (BP). (a) Effect of titration on seated systolic BP (SeSBP). (b) Effect of titration on seated diastolic BP (SeDBP). Data are mean \pm standard error of the mean. AML, amlodipine; HCTZ, hydrochlorothiazide; OM, olmesartan medoxomil.

At Week 52/ET, 63.3\% (259/409) of Black patients and $67.8 \%(856 / 1263)$ of non-Black patients in the OLE achieved the SeBP goal, although more Black patients were titrated to higher dosages. Approximately $20 \%$ of Blacks remained on the initial dose of AML $5 \mathrm{mg}+\mathrm{OM} 40 \mathrm{mg}$ per day, compared with $34.9 \%$ of non-Blacks (Table 1). In Black patients, $35.9 \%$ were uptitrated to the AML $10 \mathrm{mg}+$ OM $40 \mathrm{mg}+$ HCTZ $25 \mathrm{mg}$ per day dose level, and $49.7 \%$ on this dose level achieved their SeBP goal at Week 52/ET (Figure 3). Of non-Black patients, $82.5 \%$ who remained on the initial dose of AML $5 \mathrm{mg}+\mathrm{OM} 40 \mathrm{mg}$ per day achieved their SeBP goal at Week 52/ET. For non-Black patients titrated to AML $10 \mathrm{mg}+\mathrm{OM} 40 \mathrm{mg}+$ HCTZ $25 \mathrm{mg}$ per day, $44.5 \%$ reached the SeBP goal at Week 52/ET (Figure 3).

The mean incremental changes in SeBP due to dose titration are shown in Figure 4. In Black patients, the greatest incremental SeBP reductions were observed in patients switching from AML $10 \mathrm{mg}+\mathrm{OM} 40 \mathrm{mg}+\mathrm{HCTZ} 12.5 \mathrm{mg}$ per day to AML $10 \mathrm{mg}+\mathrm{OM} 40 \mathrm{mg}+\mathrm{HCTZ} 25 \mathrm{mg}$ per day, and in non-Black patients, incremental SeBP reductions were similar for all dose titrations.

\section{Effect of diabetes status}

At Week 52/ET, SeBP reductions from baseline in patients with diabetes were $34.2 / 19.9 \mathrm{~mm} \mathrm{Hg}$ compared with $32.1 / 19.6 \mathrm{~mm} \mathrm{Hg}$ in patients without diabetes (Figure 2). At Week 52/ET, 26.9\% (61/227) of patients with diabetes achieved the strict SeBP goal of $<130 / 80 \mathrm{~mm} \mathrm{Hg}$ and $72.9 \%$ (1054/1445) of patients without diabetes achieved their SeBP goal of $<140 / 90 \mathrm{~mm} \mathrm{Hg}$. By Week 52/ET, 48.0\% of patients with diabetes were titrated to AML $10 \mathrm{mg}+\mathrm{OM}$ $40 \mathrm{mg}+$ HCTZ $25 \mathrm{mg}$ per day and $21.1 \%$ (23/109) achieved an SeBP goal of $<130 / 80 \mathrm{~mm} \mathrm{Hg}$ (Figure 3).

Uptitration of treatment from AML $10 \mathrm{mg}+\mathrm{OM}$ $40 \mathrm{mg}+$ HCTZ $12.5 \mathrm{mg}$ per day to AML $10 \mathrm{mg}+\mathrm{OM}$ $40 \mathrm{mg}+$ HCTZ $25 \mathrm{mg}$ per day resulted in the greatest SeBP reductions, irrespective of diabetes status (Figure 4). Reductions in SeSBP in patients with diabetes ranged from 5.2 to $9.5 \mathrm{~mm} \mathrm{Hg}$, and reductions in SeDBP ranged from 3.0 to $4.6 \mathrm{~mm} \mathrm{Hg}$ (Figure 4). Reductions in SeSBP in patients without diabetes ranged from 7.7 to $10.1 \mathrm{~mm} \mathrm{Hg}$, and reductions in SeDBP ranged from 4.9 to $6.5 \mathrm{~mm} \mathrm{Hg}$.

\section{Safety}

This OLE study did not identify any safety concerns that had not previously been identified in the 8-week double-blind study. ${ }^{8}$ The adverse event profiles presented by the patients were those expected for each component monotherapy independently. There did not appear to be any unexpected drug-related adverse events with any combination of treatment regimens in any of the subgroups (data not shown). As reported earlier, ${ }^{11}$ peripheral edema, a known side effect of the use of AML, ${ }^{14}$ was lower during the OLE compared with the double-blind portion. ${ }^{8}$ Specifically, drugrelated edema occurred in 7.0, 11.1, 9.1 and $10.7 \%$ of patients receiving AML $5 \mathrm{mg}+\mathrm{OM} 40 \mathrm{mg}$ per day, AML $10 \mathrm{mg}+\mathrm{OM} 40 \mathrm{mg}$ per day, AML $10 \mathrm{mg}+\mathrm{OM}$ $40 \mathrm{mg}+$ HCTZ $12.5 \mathrm{mg}$ per day and AML $10 \mathrm{mg}+\mathrm{OM}$ $40 \mathrm{mg}+$ HCTZ $25 \mathrm{mg}$ per day, respectively. ${ }^{11}$ 


\section{Discussion}

This OLE of the COACH study used a titrate-togoal scheme to more accurately resemble current recommendations and clinical practice. ${ }^{15,16}$ After completion of the 8-week double-blind period, all patients enrolled in the 44-week OLE started on AML $5 \mathrm{mg}+\mathrm{OM} 40 \mathrm{mg}$ per day, and if BP goal was not met, they could be titrated to the next dose level of the study. This design allowed for assessment of the effectiveness of the component therapies as well as showing how well investigative sites therapeutically treated their patients with the objective of having them reach JNC 7-defined BP goals of $<140 / 90$ or $<130 / 80 \mathrm{~mm} \mathrm{Hg}$ for patients with diabetes. ${ }^{3}$

The main finding of the OLE of COACH is that the antihypertensive effects of AML $+\mathrm{OM} \pm$ HCTZ regimens were well maintained during the 44-week follow-up period in all three patient subgroups whose hypertension is generally considered difficult-to-treat. Importantly, titration to higher dosages of OM + AML, and the addition of HCTZ, resulted in greater SeBP reductions with each titration step. The achievement of SeBP goals was higher at Week 52/ ET than in the 8-week double-blind portion of the study in all patient subgroups and for all drug combinations, indicating the value of adding a third antihypertensive agent. The incremental improvements in BP control throughout the OLE period were attributable to the algorithmic treatment plan.

The excellent SeBP goal attainment in the OLE of COACH was achieved despite the fact that some investigators did not titrate to the next dose level in patients with SeBP above treatment goal, as required by the study protocol. Failure to add medications or increase dosages of existing medications when treatment goals remain unmet is termed 'clinical inertia' and is thought to account for as much as $\sim 20 \%$ of failure to achieve BP control in clinical practice. ${ }^{17,18}$ Clinical inertia also occurs in clinical trials and even when patients are compliant with their therapy. ${ }^{19}$ Clinical inertia was manifest in the OLE of the COACH study, as at the end of the study (Week 52/ET), 20\% of patients who remained on AML $5 \mathrm{mg}+\mathrm{OM} 40 \mathrm{mg}$ per day had not achieved their SeBP goal and were candidates for titration therapy that was never administered. ${ }^{11}$ It is likely that control rates would have been even higher had the titration scheme specified in the protocol been followed more closely. In addition, it is also possible that patients uptitrated to AML $10 \mathrm{mg}+\mathrm{OM}$ $40 \mathrm{mg}+\mathrm{HCTZ} 25 \mathrm{mg}$ per day and still not at BP goal may have had resistant hypertension and were unable to respond to a combination of three antihypertensive drugs.

Overall, BP control in each of the difficult-to-treat subgroups studies analysed in the OLE of COACH was greater than that reported in the National Health and Nutrition Examination Survey (NHANES). ${ }^{20}$ The overall percentage of patients aged $\geqslant 65$ years achieving their BP goal at Week 52/ET on combinations of AML $+\mathrm{OM}$ was $61.0 \%$. It is well known that as age increases, hypertension is often harder to control. ${ }^{21}$ The high BP goal achievement in the $\geqslant 65$ years of age patient subgroup supports the use of combination AML $+\mathrm{OM} \pm$ HCTZ therapy in the elderly.

Similar benefits were observed in Black patients, $63.3 \%$ of whom achieved BP goal at Week 52/ET using combinations of AML $+\mathrm{OM} \pm$ HCTZ. These data support the use of AML $+\mathrm{OM} \pm$ HCTZ in Black patients with hypertension.

Nearly $27 \%$ of patients with diabetes achieved the American Diabetes Association-recommended BP goal of $<130 / 80 \mathrm{~mm} \mathrm{Hg},{ }^{3}$ though slightly lower than the goal rate in the NHANES report $(37.5 \%) .{ }^{20}$ The challenge of achieving this strict SeBP goal of $<130 /$ $80 \mathrm{~mm} \mathrm{Hg}$ is reflected by the higher dose levels to which patients with diabetes were titrated: in this study, $48 \%$ of patients with diabetes were titrated to AML $10 \mathrm{mg}+$ OM $40 \mathrm{mg}$ + HCTZ $25 \mathrm{mg}$ per day, and only $21.1 \%$ of this group achieved the stringent SeBP goal of $<130 / 80 \mathrm{~mm} \mathrm{Hg}$ at Week $52 /$ ET. The mean SeBP achieved at Week 52/ET increased with each titration step, likely due to the fact that, in general, titration was only needed in subjects where the baseline SeBP was higher initially. Consequently, the change from baseline in SeSBP was greater with the higher doses of component drugs and with the triple drug regimen, reinforcing recommendations that patients with SeSBP $\geqslant 20 \mathrm{~mm} \mathrm{Hg}$ above goal initiate combination therapy as a first step. ${ }^{3,22}$

Combinations of antihypertensive drugs with different mechanisms of action, such as an ARB $(\mathrm{OM})$ added to a dihydropyridine CCB $(\mathrm{AML})^{8}$ or to a thiazide diuretic (HCTZ) ${ }^{23}$ have been shown to have additive effects on BP and may even ameliorate adverse effects that are specific for the component monotherapies. ${ }^{24-26}$ In this study, the similar adverse event profiles across treatment regimens and within subgroups support this conclusion. Dihydropyridine CCBs and thiazide diuretics decrease BP through reduction of peripheral vascular resistance and induction of natriuresis, respectively, which activate the renin-angiotensinaldosterone system, thus decreasing their BP-lowering effects. However, this is counteracted by the addition of ARBs that block the action of angiotensin II at the $\mathrm{AT}_{1}$ receptor, further inducing additional vasodilation, sodium and water excretion and BP reduction. ${ }^{25,27}$

In conclusion, the 44-week, OLE of the COACH study showed that long-term administration of the combination of AML $+\mathrm{OM} \pm$ HCTZ is efficacious, safe and well tolerated in difficult-to-treat subgroups of patients with hypertension. The regimen of multiple hypertensive therapies with differing mechanisms of action provides additive benefit in $\mathrm{BP}$ control and achievement of guideline-recommended BP goals without compromising patient safety. 
What is known about this topic

- In patients with hypertension, $<50 \%$ of patients aged $\geqslant 65$ years, $<53 \%$ of Blacks and $<38 \%$ of patients with diabetes reach the recommended $\mathrm{BP}$ goal of $<140 / 90 \mathrm{~mm} \mathrm{Hg}$ ( $<130 / 80 \mathrm{~mm} \mathrm{Hg}$ for patients with diabetes).

- Combination therapy improves BP goal achievement in patients with hypertension.

- The combination of amlodipine and olmesartan medoxomil significantly improves BP in the short term.

What this study adds

- The combination of amlodipine besylate and olmesartan medoxomil maintains its efficacy long term.

- Patients with difficult-to-treat hypertension such as those aged $\geqslant 65$ years, Blacks and patients with diabetes respond well to the combination of amlodipine besylate and olmesartan medoxomil with the addition of HCTZ as needed and derive additive BP-lowering effects from each of the component therapies.

- The combination of amlodipine besylate and olmesartan medoxomil \pm HCTZ can potentially enable more patients aged $\geqslant 65$ years, Black patients or those with diabetes to achieve recommended BP goals than current treatment regimens without compromising patient safety.

\section{Conflict of interest}

Suzanne Oparil, MD, is the recipient of grants-inaid from Daiichi Sankyo, Inc., Forest Laboratories, Novartis, and Takeda Pharmaceuticals. Dr Oparil is a consultant for Boehringer Ingelheim, BristolMyers Squibb, Daiichi Sankyo, Inc., NicOx, Novartis, Forest Laboratories, sanofi-aventis, and The Salt Institute. Steven G Chrysant, MD, has received research grants from Daiichi Sankyo, Inc., Novartis, Boehringer Ingelheim, Merck, Bristol-Myers Squibb, and Takeda Pharmaceuticals and serves as a consultant to Daiichi Sankyo, Inc., Novartis, and Boehringer Ingelheim. Michael Melino, $\mathrm{PhD}$, James Lee, PhD, Sulekha Karki, BAMS, and Reinilde Heyrman, MD, are all employees of Daiichi Sankyo, Inc.

\section{Acknowledgements}

This study was supported by Daiichi Sankyo, Inc. We thank Jennifer M Kulak, PhD, and Christopher J Jones, PhD, of Wolters Kluwer for providing editorial assistance in the preparation of this paper.

\section{References}

1 Whitworth JA. 2003 World Health Organization (WHO)/International Society of Hypertension (ISH) statement on management of hypertension. J Hypertens 2003; 21: 1983-1992.

2 Lewington S, Clarke R, Qizilbash N, Peto R, Collins R. Age-specific relevance of usual blood pressure to vascular mortality: a meta-analysis of individual data for one million adults in 61 prospective studies. Lancet 2002; 360: 1903-1913.
3 Chobanian AV, Bakris GL, Black HR, Cushman WC, Green LA, Izzo Jr JL et al. Seventh report of the Joint National Committee on Prevention, Detection, Evaluation, and Treatment of High Blood Pressure. Hypertension 2003; 42: 1206-1252.

4 Cushman WC, Ford CE, Cutler JA, Margolis KL, Davis $\mathrm{BR}$, Grimm RH et al. Success and predictors of blood pressure control in diverse North American settings: the antihypertensive and lipid-lowering treatment to prevent heart attack trial (ALLHAT). J Clin Hypertens (Greenwich) 2002; 4: 393-404.

5 Julius S, Kjeldsen SE, Weber M, Brunner HR, Ekman S, Hansson L et al. Outcomes in hypertensive patients at high cardiovascular risk treated with regimens based on valsartan or amlodipine: the VALUE randomised trial. Lancet 2004; 363: 2022-2031.

6 Dahlof B, Sever PS, Poulter NR, Wedel H, Beevers DG, Caulfield $\mathrm{M}$ et al. Prevention of cardiovascular events with an antihypertensive regimen of amlodipine adding perindopril as required versus atenolol adding bendroflumethiazide as required, in the AngloScandinavian Cardiac Outcomes Trial-Blood Pressure Lowering Arm (ASCOT-BPLA): a multicentre randomised controlled trial. Lancet 2005; 366: 895-906.

7 Jamerson K, Weber MA, Bakris GL, Dahlof B, Pitt B, Shi V et al. Benazepril plus amlodipine or hydrochlorothiazide for hypertension in high-risk patients. $N$ Engl $J$ Med 2008; 359: 2417-2428.

8 Chrysant S, Melino M, Karki S, Lee J, Heyrman R. The combination of olmesartan medoxomil and amlodipine besylate in controlling high blood pressure: $\mathrm{COACH}$, a randomized, double-blind, placebo-controlled, 8-week factorial efficacy and safety study. Clin Ther 2008; 30: 587-604.

9 Oparil S, Lee J, Karki S, Melino M. Subgroup analyses of an efficacy and safety study of concomitant administration of amlodipine besylate and olmesartan medoxomil: evaluation by baseline hypertension stage and prior antihypertensive medication use. J Cardiovasc Pharmacol 2009; 54: 427-436.

10 Chrysant SG, Lee J, Melino M, Heyrman R. Efficacy and tolerability of amlodipine plus olmesartan medoxomil in patients with difficult-to-treat hypertension. J Hum Hypertens 2010; 24: 730-738.

11 Chrysant SG, Oparil S, Melino M, Karki S, Lee J, Heyrman R. Efficacy and safety of long-term treatment with the combination of amlodipine besylate and olmesartan medoxomil in patients with hypertension. J Clin Hypertens (Greenwich) 2009; 11: 475-482.

12 Franklin SS. Systolic blood pressure: it's time to take control. Am J Hypertens 2004; 17: 49S-54S.

13 Zanchetti A, Ruilope LM. Antihypertensive treatment in patients with type-2 diabetes mellitus: what guidance from recent controlled randomized trials? J Hypertens 2002; 20: 2099-2110.

14 Messerli FH. Vasodilatory edema: a common side effect of antihypertensive therapy. Curr Cardiol Rep 2002; 4: 479-482.

15 Blackshear JL, Schwartz GL. Step care therapy for hypertension in diabetic patients. Mayo Clin Proc 2001; 76: 1266-1274.

16 Ofili EO. Dispelling the myth of 'aggressive' antihypertensive therapy. J Clin Hypertens (Greenwich) 2006; 8: 4-11. 
17 Phillips LS, Branch WT, Cook CB, Doyle JP, El-Kebbi IM, Gallina DL et al. Clinical inertia. Ann Intern Med 2001; 135: 825-834.

18 Okonofua EC, Simpson KN, Jesri A, Rehman SU, Durkalski VL, Egan BM. Therapeutic inertia is an impediment to achieving the Healthy People 2010 blood pressure control goals. Hypertension 2006; 47: 345-351.

19 Moser M. Physician or clinical inertia: what is it? Is it really a problem? And what can be done about it? J Clin Hypertens (Greenwich) 2009; 11: 1-4.

20 Ong KL, Cheung BM, Man YB, Lau CP, Lam KS. Prevalence, awareness, treatment, and control of hypertension among United States adults 1999-2004. Hypertension 2007; 49: 69-75.

21 Weber MA. Angiotensin II receptor blockers in older patients. Am J Geriatr Cardiol 2004; 13: 197-205; quiz 206-207.

22 Mancia G, De Backer G, Dominiczak A, Cifkova R, Fagard R, Germano G et al. 2007 Guidelines for the Management of Arterial Hypertension: the Task Force for the Management of Arterial Hypertension of the European Society of Hypertension (ESH) and of the European Society of Cardiology (ESC). J Hypertens 2007; 25: 1105-1187.
23 Oparil S, Chrysant SG, Kereiakes D, Xu J, Chavanu KJ, Waverczak W et al. Results of an olmesartan medoxomil-based treatment regimen in hypertensive patients. J Clin Hypertens (Greenwich) 2008; 10: 911-921.

24 Law MR, Wald NJ, Morris JK, Jordan RE. Value of low dose combination treatment with blood pressure lowering drugs: analysis of 354 randomised trials. BMJ 2003; 326: 1427.

25 Bakris GL. Combined therapy with a calcium channel blocker and an angiotensin II type 1 receptor blocker. J Clin Hypertens (Greenwich) 2008; 10: 27-32.

26 Chrysant SG. Proactive compared with passive adverse event recognition: calcium channel blocker-associated edema. J Clin Hypertens (Greenwich) 2008; 10: 716-722.

27 Haller H. Effective management of hypertension with dihydropyridine calcium channel blocker-based combination therapy in patients at high cardiovascular risk. Int J Clin Pract 2008; 62: 781-790.

This work is licensed under the Creative Commons Attribution-NonCommercial-No Derivative Works 3.0 Unported License. To view a copy of this license, visit http://creativecommons. org/licenses/by-nc-nd/3.0/ 